\title{
A APROPRIAÇÃO DA LINGUAGEM ESCRITA E O TRABALHO ALFABETIZADOR NA ESCOLA
}

\author{
CECÍLIA MARIA GOULART \\ Programa de Pós-Graduação e Educação da Universidade Federal Fluminense \\ Coordenadora do GT Alfabetização, Leitura e Escrita da ANPEd
}

\begin{abstract}
RESUMO
O artigo apresenta um estudo do processo de produção de textos escritos vivenciado por dez crianças de 6 anos em uma classe de alfabetização. O trabalho pedagógico realizado pela professora tem relevância teórica e metodológica para este estudo. Dois objetivos foram definidos: (i) caracterizar as estratégias utilizadas pelas crianças para se aproximarem das convenções do sistema de escrita, notadamente, o princípio alfabético e a segmentação do texto em palavras; e (ii) caracterizar a atividade de elaboração e reelaboração do conhecimento lingüistico, evidenciando a atividade epilingüistica das crianças e deixando emergir o sujeito da/na linguagem. São analisados $/ 15$ textos, produzidos ao longo de um semestre. É utilizada uma metodologia de investigação indiciária, com base em Ginzburg (1989). A análise dos dados apontou estratégias singulares e estratégias comuns de aproximação do sistema de escrita pelas crianças. Os saberes advindos dos textos escritos a que as crianças têm acesso, principalmente, organizaram as suas produções. A atividade epilingüistica se manifestou durante todo o perío do estudado, em vários níveis. Concluo que o percurso de produção dos textos escritos é próprio de cada sujeito: o processo funda-se na escrita social e converge para a escrita social por caminhos singulares.

ALFABETIZAÇÃO-MÉTODO DEALFABETIZAÇÃO-ESCR/TA
\end{abstract}

\section{ABSTRACT}

THEBEGINNINGS OF WRITING AND PEDAGOGICAL WORK. The article presents a study on the process of production of texts written by ten children, during school time, in the elementary class, attended by six years old children. The pedagogical work of the children's teacher is theoretically and methodologically relevant to the study. Two aims were defined: (i) to characterize the strategies used by children to come close to the conventions of the writing system, specially the alphabetic principle and the segmentation of the text in words; and (ii) to characterize the continuous activity of elaboration and reelaboration of linguistic knowledge, from where we think the subject in/of the language. A corpus of I I 5 texts produced along a semester was analyzed. The methodology utilized is that of indicial investigation, based on Ginzburg (1989). The analysis of the data showed the children's singular and general strategies to come close to the writing system. The children's production is organized, chiefly, according to knowledge originated from the written texts accessible to them. The children's epilinguistic activity was expressed during the whole semester, on different levels. The analysis of the children's procedures pointed out that the process of constructing up written texts is peculiar to each subject; the process is based on socia/ writing and tends toward social writing, in individually different ways.

O texto é parte dos resultados da pesquisa, financiada pelo CNPq, "Era uma vez os sete cabritinhos: a gênese do processo de produção de textos escritos", apresentada como tese de doutorado ao Departamento de Letras da PUC-Rio, em março de 1997. O trabalho também foi apresentado na 50ª Reunião Anual da SBPC, em julho de 1998, em Natal (RN), com o patrocínio da Fundação de Amparo à Pesquisa do Estado do Rio de Janeiro - Faperj. 


\section{INTRODUÇÃO}

A apropriação da linguagem escrita, na perspectiva das práticas sociais letradas, vem sendo estudada como uma aprendizagem conceitual de grande complexidade. $\bigcirc$ trabalho pedagógico realizado nas classes de alfabetização, em geral, não se tem mostrado suficiente para formar leitores e escritores proficientes. As crianças aprendem a decodificar letras em sons, no caso da leitura, e a codificar sons em letras no caso da escrita, sem no entanto produzir sentido nessas atividades. Assim, não conseguem dar conta da leitura e da produção de textos socialmente legitimados.

Tradicionalmente, o ato de alfabetizar tem sido orientado pela escolha de um método', em que há uma seqüência de passos a serem seguidos. Esses métodos são regulados pela escolha de uma unidade lingüística básica, que pode ser o fonema, a sílaba, a palavra, guiados por um critério de gradação de fonemas e de padrão silábico. Em geral, parte-se de fonemas que mantêm uma relação biunívoca com o grafema (considerados os mais fáceis) e do padrão silábico canônico consoante+vogal (CV), ou de sílabas formadas por uma única vogal (V). A língua escrita é considerada como um código de transcrição da língua oral, como se houvesse um isomorfismo entre estruturas sonoras e escritas. Os textos a que a criança tem acesso limitam-se às palavras possíveis de serem formadas com as sílabas ensinadas a cada momento do método. Isso faz com que sejam gerados conjuntos de frases, de um modo geral, estranhos ao conjunto de textos socialmente utilizados. Muitos pesquisadores têm criticado os métodos tradicionais de alfabetização e as concepções de sujeito, texto, linguagem, entre outras, que lhes estão subjacentes (Abaurre-Gnerre et al., 1985; Abaurre, 1987; Geraldi, 1985; Dietzsch, 1991).

Kato (1985) destaca a grande preocupação que os educadores têm por "métodos" de alfabetização como um instrumento seguro para ensinar a ler e a escrever. A autora salienta que para a grande maioria dos professores o método "é definido meramente como um conjunto de materiais, técnicas e procedimentos para se atingir um fim, isto é, um conjunto programado de atividades para o professor e o aluno" (p.3-4). A autora adverte que um método para ser eficaz deve ter a ele subjacentes hipóteses claras sobre a natureza do objeto a ser aprendido e sobre a natureza da aprendizagem desse objeto. Ressalta ainda que é necessário que o professor conheça plenamente tais hipóteses para que reformule sua metodologia com base em evidências encontradas em sua prática.

Os métodos sintéticos de alfabetização, muito usados na prática tradicional, se coadunam, em grande parte, com o que é proposto por Bloomfield (apud Abaurre,

I. Em Soares (1989), a autora desenvolve uma excelente pesquisa sobre a produção acadêmica a respeito da alfabetização no período de 1950 a 1986, que revela a predominância do tema método (paradigmas didáticos tradicionais), nos anos 50 e 60, seu progressivo e acentuado decréscimo, nos anos 70 e 80, e o crescimento significativo da produção sobre o tema proposta didática (atribuído a propostas baseadas em novos paradigmas didáticos); em Soares (1990), a autora discute a questão do uso de métodos tradicionais pelos professores e a possibilidade de revisão desses à luz de novos referenciais teóricos. 
1994). Segundo o autor, o planejamento do ensino das primeiras letras deveria garantir que as crianças fossem aprendendo de maneira organizada a relação entre sons e letras, do mais fácil para o mais complexo, a partir de pares mínimos de palavras, em que a comutação de um único elemento acarrete distinção fonológica e, também, semântica. A posição de Abaurre (1994), que vai ao encontro do que expressa Kato no parágrafo anterior, é que a indicação de Bloomfield não se sustenta na teoria lingüística, propriamente, mas na interface da teoria lingüística estruturalista com os pressupostos psicológicos behavioristas, vigentes na época, gerando uma visão equivocada e ingênua do processo de aquisição da língua escrita.

O fato é que a fundamentação behaviorista, associada a uma concepção de linguagem descolada do sujeito que a constitui, entre outras coisas, determinou métodos de ensino/aprendizagem da língua escrita que dissimulam o trabalho de elaboração cognitiva das crianças no esforço de aprender a ler e a escrever. $\bigcirc$ avanço das pesquisas em várias áreas de conhecimento vem permitindo acumular evidências sobre o papel ativo dos sujeitos nesse processo, em que eles mesmos e o contexto de produção de linguagem são marcados por injunções individuais e coletivas, culturais e históricas.

Ferreiro, por exemplo, vem investigando a psicogênese da língua escrita, com base na teoria piagetiana, e afirma, em artigo de 1994, que são necessários dois tipos de evidência para dar suporte a uma teoria construtivista do letramento: primeiro, que as crianças apresentem formas sistemáticas de pensar que não possam ser atribuídas a alguma informação, implícita ou explícita, dada por adultos ou por estimulação ambiental; e segundo, que, a despeito da imprevisibilidade de algumas ocasiões que as crianças têm para obter informação (interagir com material impresso, trocar impressões com outras crianças, adivinhar, ou ser impedidas de fazê-lo em contextos formais de aprendizagem, e assim por diante), encontra-se uma ordem nos problemas enfrentados e nas soluções propostas pelas crianças. Segundo a autora, há evidência acumulada em grande número de pesquisas, em vários países, de que ambas as condições são preenchidas no desenvolvimento do letramento.

É importante observar que desafios cognitivos diferenciados se colocam quando, por um lado, se pede a uma criança que escreva palavras ou frases soltas (como no caso da pesquisa experimental de Ferreiro), e, por outro, que produza textos, considerando uma proposta de produção da própria criança ou de outrem e todas as habilidades e conhecimentos que a atividade de escrever textos envolve (cf. Smolka, 1988, p.75).

Estudos de vários autores apontam que os conhecimentos das crianças não são organizados como o conhecimento convencional dos adultos. As crianças aprendem sobre letras, sons, palavras, produção/compreensão de textos, ao mesmo tempo, e em várias ordens, como também desenvolvem estratégias de monitoramento e de autocorreção (Sulzby, 1992), em contraste com a visão de que a construção da linguagem escrita seria adquirida como uma seqüência universal, organizada de estágios.

No mesmo artigo referido, Sulzby informa, com base em suas pesquisas, que foram 
observadas diferenças nos modos como as crianças escrevem sob diferentes condições. Esses resultados indicam que as crianças não têm uma concepção única da natureza da escrita, mas diferentes concepções simultaneamente. Segundo a autora, as crianças vão construindo um repertório de conhecimentos sobre a língua escrita de que fazem uso seletivamente para fazer coisas diferentes.

Estudos fundamentados no que se tem chamado "escrita inventada", ou escrita espontânea ${ }^{2}$, vêm evidenciando que as crianças realizam segmentações na escrita que não necessariamente se iniciam na sílaba ou no fonema e fazem julgamentos de acordo com princípios bem diferentes daqueles que orientam a escrita padrão (Read, 1975; Chomsky, 1979; Clarke, apud Adams, 1992).

Esses estudos sugerem um processo de apropriação da escrita marcado pela descontinuidade e pela heterogeneidade. Os conhecimentos não se vão acumulando, num sentido uniforme e unidirecional: uns se constituem, enquanto outros são destituídos, mas podem reaparecer mais tarde, e soluções de naturezas diferentes para um mesmo problema podem coexistir e até conviver num mesmo contexto.

Este artigo expõe parte dos resultados de uma pesquisa realizada como tese de doutorado (Pacheco, 1997), expandindo estudos anteriores (Pacheco 1992; 1994; 1996). Nesses primeiros estudos observo que no processo de produção de textos escritos, desde as primeiras produções:

- as crianças estão continuamente reelaborando seus conhecimentos, ao procurar meios de organizar os seus textos;

- as crianças, ao lidarem com as múltiplas demandas da elaboração do texto escrito, possuem pouco distanciamento reflexivo para realizá-lo como uma atividade com o outro, envolvidas que estão com a construção do objeto textual propriamente dito;

- o percurso de construção do objeto textual é próprio a cada sujeito;

- as crianças orientadas por trabalhos pedagógicos distintos elaboram questões relativas à produção do texto escrito de modo também distinto.

Tomando as questões acima como problematizadoras de meu estudo, instituo como hipótese de trabalho que o percurso de construção do objeto textual é próprio a cada sujeito.

Parto do pressuposto de que a constituição da linguagem escrita pela criança: (a) faz parte do processo geral de constituição da linguagem (Abaurre, 1988); e (b) se dá como um trabalho contínuo de elaboração cognitiva, pela significação que a escrita passa a ter, pela inserção e interação sociais da criança.

2. "Escrita inventada" ou espontânea é a escrita realizada espontaneamente pela criança, motivada pela necessidade de expressão verbal e pelo significado da mesma no contexto de produção, sem que se reforce a necessidade de correção ortográfica. 
A aquisição da escrita, nesse caso, está sendo pensada como um processo que dá continuidade ao desenvolvimento lingüístico da criança. Esta se apropria de uma outra forma de organização das experiências e de interação com a sociedade a que pertence. A relação língua oral/língua escrita é considerada como um continuum altamente heterogêneo, motivado pelos usos e funções diferenciados que as diferentes camadas sociais fazem das duas modalidades e pela variação padrão/não padrão (Stubbs, 1982; Chafe, 1985; Tannen, 1985; Kato, 1987; Terzi, 1995). Assim, é possível pensar tanto em descontinuidade funcional quanto em descontinuidade formal.

conceito de linguagem, em conseqüência, se mostra fundamental, tanto para este estudo como para se conceber a prática alfabetizadora. Segundo Franchi (1992), a linguagem é um trabalho coletivo em que cada um se identifica com os outros e a eles se contrapõe, seja assumindo a história e a presença, seja exercendo suas opções solitárias. A linguagem é um sistema simbólico mediante o qual se opera sobre a realidade, dado que organiza a realidade como um sistema de referências. Em Franchi (1986), compreende-se que não há condições para uma linguagem se constituir fora da interação - "é, pois, na atividade do sujeito com os outros, sobre os outros e com o mundo que a linguagem se constitui" (p. 32). As condições de produção da linguagem, em conseqüência, assumem papel relevante na sua constituição.

Pode-se assim pensar ao mesmo tempo a ação do sujeito na linguagem e a ação da linguagem no sujeito: a linguagem constituindo-se no sujeito e sendo constituída pelo sujeito abre a perspectiva de pensar o sujeito na linguagem e da linguagem. Desse modo, é possível postular que as crianças no processo de apropriação da linguagem escrita deixem marcas das suas atividades na construção dessa modalidade de linguagem.

Tomando como eixo a hipótese que orienta este estudo e a concepção de linguagem esboçada acima, os objetivos deste trabalho são: (a) caracterizar as estratégias utilizadas pelas crianças (i) para se aproximarem do princípio alfabético do sistema de escrita e (ii) para segmentar o texto em palavras; e (b) caracterizar a atividade epilingüística das crianças, isto é, a atividade de reflexão sobre aspectos da produção de textos no momento da escrita. Segundo Geraldi (199|,p. 24), a atividade epilingüística, independentemente da consciência ou não, indicando uma reflexão sobre algum aspecto do material lingüístico em produção, suspende o tratamento do tema a que se dedicam os interlocutores para manipular recursos expressivos que estão sendo usados. Seria uma operação que se manifestaria nas negociações de sentido, como hesitações, autocorreções, reelaborações, rasuras, pausas longas, repetições, antecipações, lapsos etc.

\section{A INVESTIGAÇÃO INDICIÁRIA NA AQUISIÇÃO DA ESCRITA}

O método de pesquisa adotado no trabalho fundamenta-se no que Ginzburg ( 1989) caracteriza como uma metodologia de investigação indiciária. É plausível, segundo o autor, 
reconhecer a totalidade de um fenômeno, de um fato ou de uma competência, a partir de indícios qualificados do mesmo. Os indícios podem ser caracterizados como pormenores, detalhes, dados marginais, particularidades, considerados elementos reveladores do objeto em foco.

Abaurre (199|) destaca a relevância do trabalho com indícios na perspectiva da aquisição da linguagem escrita pelo que podem representar como marcas do processo que continuamente vai constituindo e modificando a complexa relação entre sujeito e linguagem, ao darem maior visibilidade a alguns aspectos desse processo. Estes indícios revelariam não só a manipulação e a reelaboração do material lingüístico pela criança, dada a plasticidade natural da linguagem, mas também as operações da criança sobre a linguagem e as hipóteses que elabora continuamente no intuito de compreender o seu funcionamento.

Sendo o processo de produção de textos escritos o foco de interesse deste trabaIho, foi realizado um estudo longitudinal com vistas a caracterizar aspectos daquele processo. Na pesquisa como um todo, foram analisados os textos escritos por dez crianças durante dois anos letivos - a classe de alfabetização, aos 6 anos, e a primeira série, aos 7 anos. Para o alcance dos objetivos definidos neste trabalho, entretanto, foram analisados os I I 5 textos produzidos pelas crianças, no período de março a agosto, na classe de alfabetização - CA. A idade média das crianças é 6 anos e 4 meses no início do ano letivo, em março de 1994. Os textos tinham padrões variados: reprodução de histórias, de parlendas, de notícias de jornal, anúncios, mensagens e outros. Ressalte-se que as mesmas propostas eram formuladas a todas as crianças.

As crianças eram de uma mesma turma de uma escola pública do Rio de Janeiro, conhecida como CAP da Uerj. Trata-se do Colégio de Aplicação Fernando Rodrigues da Silveira, pertencente à Universidade do Estado do Rio de Janeiro.

critério para a seleção das crianças foi que, ao iniciarem a CA, não tivessem estabelecido o princípio alfabético da língua escrita, organizando o que chamo "intenção de texto" ${ }^{3}$ como um aglomerado aparentemente aleatório de letras (nove crianças), ou, caso estivessem operando com o princípio alfabético, escrevessem o texto sem demarcação de palavras (uma criança).

trabalho alfabetizador realizado pela professora da turma investigada tem interesse teórico e metodológico para o meu estudo já que, opostamente ao trabalho tradicional desenvolvido em classes de alfabetização, nesta turma as crianças lêem e escrevem para aprender - a análise da língua está subordinada ao seu uso. Além disso, os usos e as funções sociais da linguagem escrita orientam as atividades cotidianas da turma. Isso quer dizer que as crianças desde o início do ano escolar são convidadas a escrever, do jeito que podem e sabem, textos socialmente significativos.

3. Como "intenção de texto"estou considerando a produção de texto pela criança, em resposta a uma proposta da professora, em que não se observam os padrões convencionais da língua escrita, embora seja lido com sentido pela criança e apresente adequação à proposta da professora. 
Essa prática pedagógica leva as crianças a escreverem de modo espontâneo, isto é, guiadas pelas hipóteses e convicções que vão desenvolvendo sobre a elaboração de textos escritos. Para explicitar melhor, talvez seja possível dizer que as crianças vão "inventando" a escrita (ver nota de rodapé 2). O que regula a produção das crianças parecem ser (a) as atividades de leitura de livros, jornais, mensagens, e muitos outros textos que circulam no espaço social, realizadas em sala pelo professor, que vão provocando os alunos não só a "ler" e conversar sobre o que está sendo lido, como também sobre a escrita de títulos ou de dados considerados significativos no material lido; e (b) as próprias atividades de produção de textos, em conjunto, em duplas e individuais, além de jogos e brincadeiras realizados com o objetivo de levar as crianças a pensarem sobre a escrita ${ }^{4}$. Estas escritas "inventadas" tornam observáveis características do processo que as crianças percorrem para se constituir em usuárias da linguagem escrita. Neste sentido, a relação sujeito-linguagem se mostra mais saliente.

Estabeleço como ponto de partida para o alcance do primeiro objetivo os conhecimentos que cada criança apresenta no primeiro texto produzido. A partir daí, as marcas na escrita que indiciem mudança de concepção de alguma ordem, ou a explicitação de conhecimentos novos, são destacadas e consideradas como dados indiciários. Para a análise da atividade epilingüística das crianças, são consideradas como indícios as marcas que revelem apagamentos (supressão de elementos do texto), oscilações (na forma de grafar uma mesma palavra repetida no texto, por exemplo), reelaborações, inserções e outras marcas que dêem visibilidade à presença do sujeito no processo de apropriação da linguagem escrita. Essas questões foram analisadas na perspectiva individual, considerando a produção de cada criança, e na perspectiva geral, analisando a produção do conjunto de crianças, evidenciando ocorrências comuns a todas.

\section{AS MARCAS DA ATIVIDADE DOS SUJEITOS NA PRODUÇÃO DA LINGUAGEM ESCRITA}

Foram inúmeras as ocorrências analisadas. Elas evidenciaram estratégias comuns aos processos de aproximação do sistema convencional de escrita pelas crianças, que podem ser vistas como recursos individuais, mas, pelo que os dados nos sugerem, com o ponto de partida nas especificidades do nosso sistema de escrita, bem como estratégias singulares.

Todas as crianças investigadas iniciaram a CA sabedoras de que a matéria-prima da escrita são as letras. Também sabiam que a escrita é orientada no papel de cima para baixo

4. No caso de crianças alfabetizadas por métodos tradicionais, genericamente falando, o que regula a produção das crianças parecem ser os textos da cartilha ou textos acartilhados, ou seja, textos em que a escrita é controlada pelos elementos lingüísticos que vão sendo apresentados, dentro dos critérios já tratados na introdução deste estudo. A produção das crianças, de um modo geral, fica limitada aos conhecimentos ensinados pela professora, deixando pouco espaço para que a reflexão espontânea das crianças sobre a escrita aflore. 
e da esquerda para a direita. Somente duas crianças realizaram, durante o período analisado, escritas da direita para a esquerda, misturadas a linhas escritas na direção convencional.

Nove estratégias foram mais caracteristicamente classificadas como comuns aos processos das crianças:

I. estratégia de organização do texto em cadeias de letras, valendo como o próprio texto (ver Texto I), ou como porções do texto (ver Texto 2);

Texto I. Gabriel ${ }^{5}$

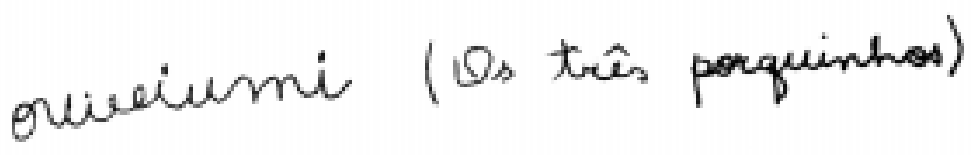

Texto 2. Camila

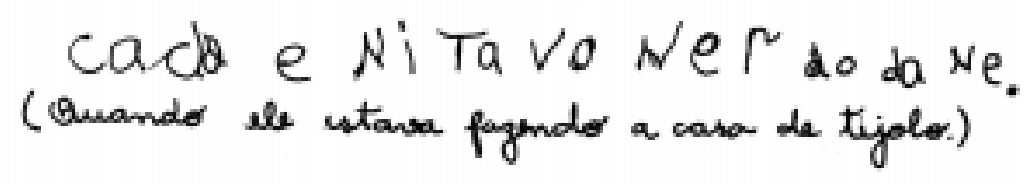

A proposta de produção destes dois textos consistia em que as crianças, após terem ouvido a história e conversado sobre ela, escrevessem a parte de que tivessem gostado mais. Nesse momento, as crianças evidenciam que, entre conhecimentos de naturezas diversas, já sabem que (a) as letras são a "matéria-prima" da escrita; e (b) se escreve da esquerda para a direita e de cima para baixo, embora este último saber não se tenha explicitado nesses dois textos. As escritas infantis nos sugerem que as crianças percebem o contínuo de letras e, entre outras coisas, estão especulando sobre o que motiva as segmentações neste contínuo.

2. estratégia de utilização de palavras e expressões legitimadas (ver Texto 3);

Essa estratégia, embora tenha caráter diferenciado em relação às outras arroladas neste estudo, foi destacada por ser, também, um recurso usado pelas crianças no processo de compor os textos (ver a seguir).

5. Todas as escritas entre parênteses representam as leituras que as crianças realizaram dos textos que produziram. 
3. estratégia de utilização de grafemas diferentes de letras (ver Texto 4);

As estratégias (2) e (3) estão intimamente ligadas. Caracterizam-se pela apresentação, nos textos iniciais, de palavras, expressões e grafemas diferentes de letras (sinais de pontuação, de acentuação), legitimados nos textos socialmente significativos a que as crianças têm acesso. Com essas estratégias as crianças legitimam os seus próprios textos, ressignificando partes e sinais observados nas escritas que os circundam.

Texto 3. Fernanda

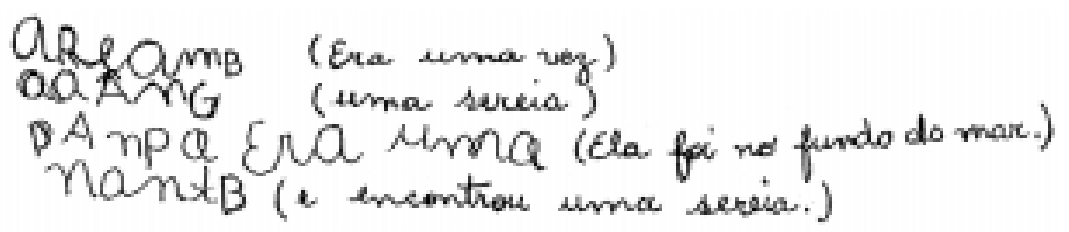

Texto 4. Marcos Vinicius

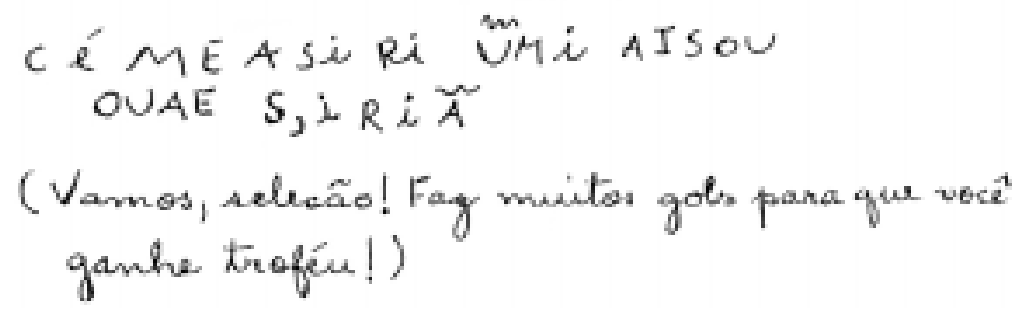

O texto 3 foi gerado do mesmo modo que os textos I e 2; o texto 4, por sua vez, foi escrito a partir do acompanhamento que as crianças fizeram, via TV e jornais, principalmente, dos preparativos da seleção nacional para disputar a Copa do Mundo. Eles organizaram um painel com mensagens de incentivo à seleção que embarcava para participar do torneio. As propostas de produção dos textos nessa classe revelam que a aprendizagem da língua escrita está intimamente relacionada aos usos e funções sociais desta modalidade de linguagem verbal.

4. estratégia de canonização de sílabas não canônicas (ver Texto 5);

As crianças regularizaram sílabas não canônicas, (isto é, sílabas diferentes de CV), formatando-as como CV. Algumas crianças utilizaram a estratégia durante algum tempo; outras somente como solução localizada para determinadas situações enfrentadas. Essa 
estratégia evidencia a atenção das crianças para as características da língua. As crianças observam o predomínio do padrão silábico CV e, ou regularizam-no para quase todas as sílabas durante algum tempo, como foi dito, ou recorrem a esse padrão em momentos de dificuldade.

A apresentação das estratégias vai evidenciando tanto a ação das crianças sobre a linguagem que estão aprendendo quanto a ação da linguagem escrita sobre a aprendizagem das crianças.

Texto 5. Fabiana

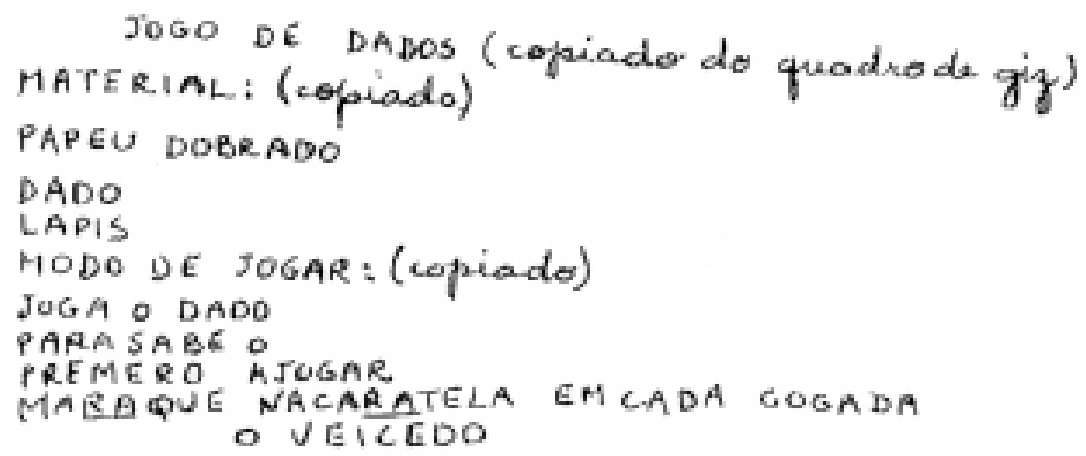

texto 5 foi produzido a partir de uma proposta de jogo apresentada pela professora. Ela discutiu com as crianças sobre as partes que compõem uma orientação para um jogo: nome do jogo, material e modo de jogar. Destacou essas partes no quadro de giz. Em seguida explicou o jogo que seria jogado. As crianças produziram o texto sobre o Jogo de Dados, registrando-o no caderno.

5. estratégia de preenchimento

À medida que as crianças iam captando mais e melhor as características dos textos escritos, iam formando imagens dos textos e de suas partes que procuravam preencher (ainda que de forma não convencional), ao elaborar seus próprios textos. Isto foi realizado principalmente de três maneiras: (a) conformando uma organização espacial adequada do texto, utilizando palavras escritas de forma não convencional; (b) escrevendo a parte das palavras que consideravam saber, e preenchendo o restante da imagem da palavra e do texto de forma idiossincrática; e ( c) escrevendo parte(s) do texto dentro de uma determinada concepção de escrita, de um modo geral, ainda não convencional, e outra(s) parte(s), usando a estratégia de preenchimento (ver Texto 6). 
Texto 6. Pâmela

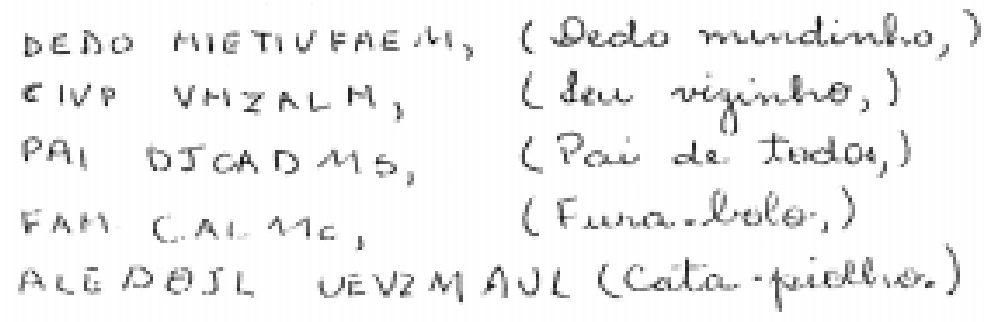

Na proposta da produção que gerou o texto 6, as crianças trabalharam com o texto da parlenda no quadro de giz, lendo-a várias vezes e brincando com o texto oralmente. Em seguida, a professora solicitou que os alunos a registrassem no caderno para não esquecer, como já haviam feito com outros textos semelhantes. Pâmela produz o texto, mantendo palavras e "palavras" em adequada organização espacial no papel; escreve corretamente as palavras DEDO e PAI (talvez com a memória do texto que viu escrito); explicita algumas letras relacionadas alfabeticamente (mas nem sempre ortograficamente) à oralidade, como o MI, de "mindinho"; o C, em "Seu"; o V, de "vizinho"; o DJ, para "de"/ "dji", como essa preposição é expressa em algumas variedades lingüísticas; o S, marca de plural de "todos"; e o F, de "Fura". Outras relações poderiam ser evocadas, mas me abstenho de trazê-las neste momento. Somente um estudo mais aprofundado que incorpore, principalmente, a interlocução com as crianças poderá levar a uma compreensão maior dessas escritas.

6. estratégia de formação de amálgamas de palavras (ver Texto 7)

As crianças organizaram escritas em que duas ou mais palavras se misturaram, formando um todo gráfico significativo. Essa estratégia se torna explícita porque a criança já compreendeu a base do sistema alfabético. É relevante observar que as crianças vão dando soluções aos problemas encontrados de um modo peculiar. Ao mesmo tempo em que revelam conhecimentos complexos sobre a escrita, do ponto de vista estrito, "tropeçam" em determinadas questões ligadas ao conhecimento da linguagem como um todo, isto é, lato sensu.

Texto 7. Fernanda

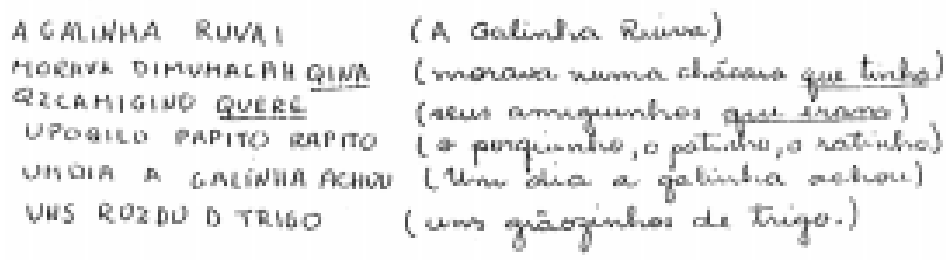


A história de Fernanda revela uma escrita praticamente alfabética (mas não ortográfica), em relação, por exemplo, à escrita de Pâmela no texto 6. Fernanda forma os amálgamas de palavras provavelmente por dificuldades de segmentação das construções relativas com o pronome "que" ( que tinha...; que eram...). Fatores prosódicos e fatores relacionados ao processamento dos textos podem estar influenciando a escrita e contribuindo para a dificuldade na referida segmentação. É plausível pensar que o processo de produção de textos possa ser descrito pelo entrecruzamento das estratégias utilizadas pelas crianças para aprender a escrever. Observa-se também que as questões que a realização do texto escrito apresenta são mais amplas que a escrita de palavras soltas e até mesmo a escrita de frases. A tensão da ação da linguagem sobre os sujeitos, bem como da ação dos sujeitos sobre a linguagem, encontra espaço para se manifestar em situações discursivas, considerando-se o texto como unidade do discurso.

7. estratégia de utilização do valor sonoro do nome da letra (ver Texto 8)

As crianças se valeram do valor sonoro do nome de algumas letras para compor palavras de seus textos. Conforme pode ser analisado, no texto abaixo de Pâmela, muitas questões de ordem fonético-fonológicas e de segmentação estão mobilizando a menina, resultando na arregimentação de muitas estratégias para a sua execução.

Texto 8. Pâmela

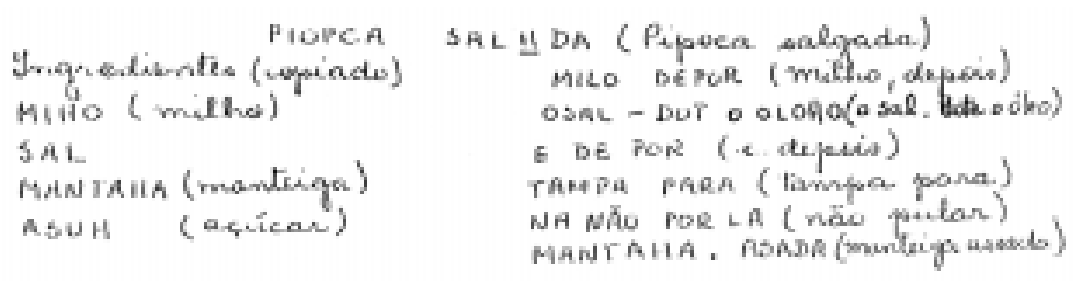

Esse texto foi produzido com base em receitas de pipoca doce e de pipoca salgada que as crianças trouxeram de suas casas. A professora ressaltou as partes desse tipo de texto, escrevendo-as no quadro, e conversou sobre as diferentes receitas. $\bigcirc$ entrecruzamento da linguagem oral com a linguagem escrita, que se estabelece por meio do diálogo, parece ter um papel importante na aprendizagem da linguagem escrita nesta sala de aula.

8. estratégia de escrita silábica (ver Texto 9)

As crianças apresentaram, durante algum tempo, ou em situações específicas, síla- 
bas das palavras representadas por uma letra. No texto de Raphael pode-se observar que a escrita silábica convive com a escrita orientada por outras hipóteses. Essa observação contribui para pensar que muitos conhecimentos e muitas estratégias estão sendo construídos/ utilizados em um mesmo momento no processo de aprendizagem.

Texto 9. Raphael

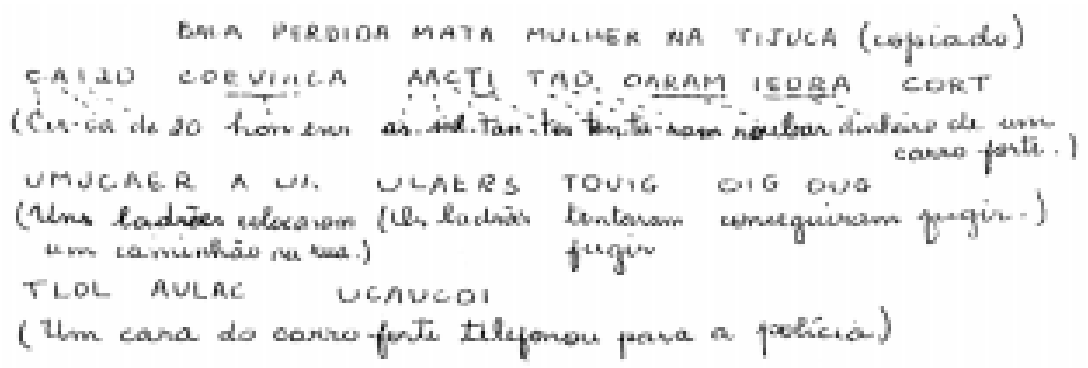

Raphael reescreve uma notícia de jornal, lida na sala de aula, a partir de seleção realizada pelas crianças, com base na leitura das manchetes de capa do jornal feita pela professora. É importante ressaltar que, embora o menino ainda não escreva alfabeticamente, ele está se apropriando do discurso da linguagem escrita. A organização morfossintática do texto, principalmente, evidencia esta marca do seu processo de letramento.

9. estratégia de utilização do próprio nome como referência para a escrita dos textos (ver Texto 10)

Nessa estratégia, a criança utiliza o conhecimento que tem das letras de seu próprio nome para escrever textos. Em geral, a criança acrescenta outras letras que já conhece ao "alfabeto" que o seu nome representa nesse momento. Essa estratégia se mostrou produtiva para algumas crianças no início da CA.

Texto 10 (fragmento). Marcos Vinicius

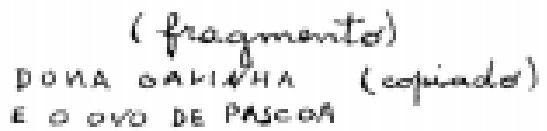

E o oVo DE PASCoA
Ivioa he Asioa (Que bonito dia para dar um passeio!) Única IAISAINCIDOSTS AROININStils. parte lida. INA NSO

IASIES NIESASIASN IVLSARAMARCOS 
Foi possível observar que muitas ocorrências denotaram estratégias que tiveram o mesmo ponto de partida, mas foram encaminhadas de modos diferenciados pelas crianças. A análise longitudinal dos dados permitiu observar processos fortemente marcados pela descontinuidade, do ponto de vista das soluções apresentadas para os problemas.

As inúmeras estratégias nomeadas singulares foram indiciadas por soluções dadas pelas crianças de forma original. Algumas dessas foram passíveis de interpretação no interior do quadro teórico configurado; outras foram deixadas em aberto - a subjetividade de cada criança falou mais alto.

As crianças procuraram se aproximar das convenções do sistema de escrita de várias maneiras. Os textos escritos a que tinham acesso se mostraram como uma fonte rica de descobertas e usos variados. $\bigcirc$ recurso à linguagem oral foi observado, em nível ortográfico, para dar solução a muitos segmentos de palavras. Esse recurso foi mais bem evidenciado em palavras cujo reflexo da variação lingüística na fala se faz notar. Do ponto de vista discursivo, entretanto, as características dos textos eram de textos planejados para serem escritos. A estratégia de recorrer à observação das marcas próprias à linguagem escrita também foi evidenciada para dar soluções localizadas em algumas partes de alguns textos.

O conhecimento da língua escrita vai sendo construído pelas crianças por meio do agenciamento de estratégias diversas ao mesmo tempo. Tais estratégias parecem organizar-se como uma arquitetura móvel, instável e aberta que vai sendo construída e modificada, em razão da gradativa definição de pertinência ao sistema de escrita e de novas necessidades. Essa arquitetura, então, se faz e se desfaz no processo de aprendizagem, de acordo com o modo como cada criança administra as soluções dadas aos problemas, sempre renovados, que surgem no processo de elaboração de textos.

As crianças vão crescentemente aprendendo a lidar com os diferentes aspectos que a produção de textos envolve, fazendo, ao mesmo tempo, micro e macroanálises daqueles aspectos. Às vezes decompõem-nos de modo intenso, outras vezes sintetizamnos, abreviando.

Os critérios de segmentação das palavras nos textos se originam na observação ativa dos textos escritos a que as crianças têm acesso pela análise morfológica que são capazes de realizar, aliada ao desenvolvimento do próprio sistema de escrita. $\bigcirc$ fatiamento do texto, de um certo modo, mostrou-se atrelado a um controle mínimo de características do sistema de escrita.

A categorização das palavras como unidades autônomas, do ponto de vista gráfico, vai dando-se aos poucos pela criança. As formas dependentes (como as preposições, p.ex.), por serem passíveis de, graficamente e, muitas vezes, semanticamente, estarem contidas em outras formas, mostraram-se mais resistentes a ser consideradas como palavras. Com isso, foram geradas hipossegmentações (segmentação a menos: de volveu 
por devolveu; dicasa por de casa, levoua por levou-a, sichamava por se chamava, p.ex.) e amálgamas de palavras. Do mesmo modo, a análise da língua com base em grupos de força, ou grupos tonais, parece ter determinado muitas dessas ocorrências.

Embora em menor número, foram também observadas muitas hipersegmentações (segmentação a mais: des cubril por descobriu, em controu por encontrou, p. ex.). Essas ocorrências se explicam porque a observação das crianças não é unidirecional. Ao desenvolverem critérios para a constituição do conceito de palavra, em geral, procuram dar conta das unidades que ficam fora da categorização por elas organizada. Assim, palavras usadas nos textos que contêm como partes iniciais ou finais de suas escritas a grafia de formas dependentes, principalmente, são passíveis de serem hipersegmentadas. Análises estruturais de outras naturezas também regularam hipersegmentações realizadas pelas crianças.

De acordo com a análise realizada, pude observar que no início do processo as crianças vão resolvendo os problemas conforme vão aparecendo. Valem-se de diferentes estratégias de forma localizada, tanto para escrever palavras como para segmentálas. Isso explica, em parte, por que num mesmo texto são encontradas soluções diferentes para problemas semelhantes. Aos poucos, as crianças vão relacionando determinadas estratégias a determinados problemas. Essas relações desenvolvidas, por sua vez, nem sempre são produtivas no sistema, considerando-se as irregularidades e idiossincrasias desse sistema.

As crianças criam as estratégias como condições para a recriação da linguagem, que elas vêem nos textos de outros autores, isto é, como condições para que surjam os seus textos individuais. É então no interior de um complexo emaranhado de conhecimentos que as crianças aprendem a escrever textos. Quanto mais as crianças vão adentrando essa rede de conhecimentos e percebendo a sua complexidade, erram mais. Isso quer dizer que neste momento do processo as crianças erram mais porque sabem mais.

A atividade epilingüística das crianças se explicitou durante todo o período investigado. A própria oscilação nas soluções utilizadas para resolver problemas semelhantes, considerada anteriormente, faz parte dessa atividade. Foram evidenciadas marcas desta atividade, não só em nível ortográfico, mas também morfológico, sintático, semântico, discursivo e também da própria organização espacial do texto no papel. Essa atividade se evidenciou em reelaborações, repetições, rasuras, inserções e por meio de recursos de configuração gráfica.

No texto II, abaixo, está exemplificada uma reelaboração realizada pela criança em nível sintático-discursivo. Ao escrever uma mensagem, por ocasião da morte do piloto Ayrton Senna, Fabiana deixa explícita a revisão que faz no texto enquanto o escreve: ela usa primeiramente a forma "ainda é" (AIDAE) que depois reelabora para "é ainda", certamente objetivando uma expressão mais enfática. 
Texto | I. Fabiana6

AYRTON SENNA

VOCE AIDAE E (Você ainda é é

AIDA TBI CAMPEÃ- ainda tricampeão.)

$\bigcirc$

Os indícios da atividade epilingüística revelam a presença das crianças que estão ali, pulsando na criação dos textos; revelam em síntese a existência de sujeitos na/da linguagem. Essa atividade se mostrou intrinsecamente atrelada ao processamento textual, relacionando-se ao monitoramento recorrente que se dá durante a produção.

\section{CONCLUSÕES}

Pode-se afirmar, em relação às crianças, que muitos fatores determinam uma compreensão maior ou menor da língua escrita como sistema. Do ponto de vista das questões analisadas neste estudo, entretanto, evidencia-se que o movimento em direção às características da escrita em língua portuguesa vistas nos textos socialmente significativos levou as crianças a construírem estratégias e hipóteses cada vez mais relevantes para a elaboração de seus próprios textos. As concepções e imagens que as crianças vão formando dos vários tipos de textos, de suas partes, de suas organizações espaciais no papel e de suas características discursivas têm um papel fundamental na escrita de seus próprios textos.

Nesse sentido, pode-se dizer que, ao analisar aspectos sobre os modos de aprender, destacam-se também aspectos de um modo de ensinar. $\bigcirc$ fato de as crianças terem tido a oportunidade de (a) ter acesso a textos legitimados socialmente; (b) poder manuseálos e ouvir as suas leituras, falar sobre eles e discuti-los; e (c ) começar a escrever do modo que sabiam, objetificando aos poucos a linguagem escrita, como condição para analisá-la, está diretamente relacionado aos resultados encontrados.

Os textos escritos a que as crianças tiveram acesso, gerados no interior de práticas sociais culturalmente determinadas, foram observados como matrizes de soluções para seus próprios textos, no início e ao longo do desenvolvimento do processo. A organização e o uso social da modalidade de linguagem escrita foram estruturantes daquela produção, ao funcionarem como organizadores de probabilidades para a construção de estratégias pelos sujeitos.

As estratégias utilizadas pelas crianças vão-se redesenhando de acordo com a transformação que se vai operando no sujeito e no objeto, no processo de aprendizagem, já que com aquela transformação se organizam esferas de necessidades diferentes.

6. Este texto foi copiado do quadro mural da sala de aula, já que não havia possibilidade de fazer uma fotocópia. 
processo de produção de textos escritos pode ser caracterizado principalmente de dois modos: como um processo de contínua e recorrente análise, marcado pela heterogeneidade e pela descontinuidade, e como um processo marcado pela presença do sujeito da/na linguagem em direção a um outro. Neste sentido, a hipótese de que o percurso de construção da linguagem escrita é próprio a cada sujeito foi confirmada.

A análise dos dados evidenciou que não é possível destacar uma ordem no processo de aprendizagem da língua escrita pelas crianças. As crianças vão complexamente se apropriando dos conhecimentos envolvidos no também complexo processo de produção de textos. Mantendo diferenças e por caminhos diferentes, as crianças vão convergindo na construção de textos escritos, atraídas pelo caráter público das convenções. Os processos fundam-se na escrita social e convergem para a escrita social por caminhos singulares.

Pelo que se pode concluir, o trabalho alfabetizador tradicionalmente realizado nas classes de alfabetização, ao simplificar um modo de ensinar, desvinculando as práticas de escrita do movimento histórico e cultural em que são geradas, escamoteia a complexidade da atividade de produção de textos escritos. Além disso, subestima a capacidade cognitiva das crianças.

Pode-se afirmar que alfabetizar é menos impor modelos que permitir que os sujeitos desenvolvam suas formas de captar o simbólico social nos textos (e aí está incluído o sistema de escrita), a partir de sua subjetividade, com a sua marca, a sua assinatura. A construção da identidade individual no processo de produção de textos parece estar fundada na construção da identidade social.

\section{REFERÊNCIAS BIBLIOGRÁFICAS}

ABAURRE-GNERRE, M. B. M. et al. Leitura e escrita na vida e na escola. Leitura: teoria e prática, Campinas, v. 4, n.6, p. I5-26, 1985.

ABAURRE, M. B. M. A Alfabetização na perspectiva da lingüística: contribuições teórico-metodológicas. Cadernos ANPEd, n.6, p. 91-124, 1994.

. Esquizofrenias. LEIA, São Paulo, p.48-9, nov. 1987.

. The Interplay between spontaneous writing and underlying linguistic representations. European Journal of Psychology of Education, v. 3, n. 4, p.4I 5-30, 1988.

Língua oral, língua escrita: interessam à lingüística, os dados da representação escrita da linguagem? Campinas, I99I. (Apres. ao IX Congresso Internacional da ALFAL, Campinas, 1991)

ADAMS, M. J. Beginning to read: thinking and learning about print. Cambridge, MA: The $M$. I. T. Press, 1992. 
BLOOMFIELD, L. Language. New York: Henry Holt and Company Inc., 1933.

CHAFE, W. L. Linguistic differences produced by differences between speaking and writing. In: OLSON, D. et al. Literacy, language and learning. the nature and consequences of reading and writing. Cambridge: C. U. P, 1985, p. 105-23.

CHOMSKY, C. Approaching reading through invented spelling. In: RESNICK, L. B. and WEAVER, P. A. (eds.). Theory and practice of early reading. Hillsdale, NJ: Erlbaum Associates, 1979. p. 43-65.

DIETZSCH, M. J. Cartilhas: a negação do leitor. In: MARTINS, M. H. (org.). Questões de linguagem. São Paulo: Contexto, 1991, p. 27-46.

FERREIRO, E. Two literacy histories: a possible dialogue between children and their ancestors. In: KELLER-COHEN, D. (ed.). Literacy, interdisciplinary conversations. Cresskill, N.J.: Hampton Press, 1994, p. I15-28.

FRANCHI, C. Linguagem: atividade constitutiva. Cadernos de Estudos Lingüísticos, Campinas, n. 22, 1992.

Reflexões sobre a modularidade da mente. Boletim da ABRALIN, São Paulo, n. 8, p. 17-35, 1986.

GERALDI, J. W. Portos de Passagem. São Paulo: Martins Fontes, 1991.

Escrita, uso da escrita e avaliação. Cadernos CEDES, São Paulo: Cortez, n. I4, p. 30-3, 1985.

GINZBURG, C. Mitos, emblemas, sinais. morfologia e história. São Paulo: Companhia das Letras, 1989.

KATO, M. A . O Aprendizado da leitura. São Paulo: Martins Fontes, 1985.

No mundo da escrita. São Paulo: Ática, 1987.

PACHECO, M. C. G. Aspectos do processo de produção de textos infantis: soluções transitórias não são erros. Escrita. Rio de Janeiro: Departamento de Letras da PUC-RJ, n. I, p. 79-87, 1996.

Da matéria bruta à linguagem escrita: o processo de Mariana. Caxambu, 1994. (Apresentado ao G.T. de Alfabetização na $17^{\text {a }}$ Reunião da ANPEd.)

Era uma vez os sete cabritinhos. a gênese do processo de produção de textos escritos. Rio de Janeiro, 1997. Tese (dout.) Departamento de Letras da PUC.

Um Estudo exploratório de aspectos do processo de produção de textos escritos por crianças de 7 anos. PUC-RJ, 1992. Dissert. (mestr.) PUC-RJ.

READ, C. Lessons to be learned from the preschool ortographer. In: LENNEBERG, E. H., 
LENNEBERG, E. (eds.). Foundations of language development. a multidisciplinary approach. New York: Academic Press, 1975, v. 2, p. 367-92.

SMOLKA, A . L. B. A Criança na fase inicial da escrita: a alfabetização como processo discursivo. São Paulo: Cortez, 1988.

SOARES, M. B. Alfabetização: em busca de um método? Educação em Revista. Belo Horizonte: Faculdade de Educação da UFMG, n.12, p. 44-50, 1990.

Alfabetização no Brasil: o estado do conhecimento. Brasília: REDUC/NEP, 1989.

STUBBS, M. Written language and society: some particular cases and general observations. In: NYSTRAND, M. (ed.). What writers know. the language, process and structure of written discourse. Orlando, Fl: Academic Press, 1982, p. 3 I-55.

SULZBY, E. Writing and reading: signs of oral and written language organization in the young child. In: TEALE, W. H., SULZBY, E. (eds.). Emergent literacy. writing and reading. Norwood, NJ: Ablex, 1992, p. 50-89.

TANNEN, D. Relative focus on involvement in oral and written discourse. In: OLSON, D., TORRANCE, N., HILDYARD, A. (eds.). Literacy, language and learning. Cambridge: Cambridge University Press, 1985, p. 124-47.

TERZI, S. B. A Oralidade e a construção da leitura por crianças de meios iletrados. In: KLEIMAN, A. B. (org.). Os Significados do letramento. Campinas: Mercado de Letras, 1995, p. $91-1 \mid 7$. 
